\title{
Ambient fine and coarse particles in Japan affect nasal and bronchial epithelial cells differently and elicit varying immune response
}

\section{$\operatorname{AUTHOR}(\mathrm{S}):$}

Onishi, Toshinori; Honda, Akiko; Tanaka, Michitaka; Chowdhury, Pratiti H.; Okano, Hitoshi; Okuda, Tomoaki; Shishido, Daiki; ... Yasuda, Makoto; Hirano, Shigeru; Takano, Hirohisa

\section{CITATION:}

Onishi, Toshinori ... [et al]. Ambient fine and coarse particles in Japan affect nasal and bronchial epithelial cells differently and elicit varying immune response. Environmental Pollution 2018, 242(Part B): 1693-1701

\section{ISSUE DATE:}

2018-11

\section{URL:}

http://hdl.handle.net/2433/243828

\section{RIGHT:}

(C) 2018. This manuscript version is made available under the CC-BY-NC-ND 4 . 0 license

http://creativecommons.org/licenses/by-nc-nd/4.0/; The full-text file will be made open to the public on 1 November 2020 in accordance with publisher's 'Terms and Conditions for Self-Archiving'.; この論文は出版社版でありません。引 用の際には出版社版をご確認ご利用ください。; This is not the published version. Please cite only the published version. 
1 Ambient fine and coarse particles in Japan affect nasal and bronchial epithelial cells differently and elicit varying immune response

3

4 Toshinori Onishi ${ }^{1,2}$, Akiko Honda ${ }^{1 *}$, Michitaka Tanaka ${ }^{1}$, Pratiti H Chowdhury ${ }^{1}$, Hitoshi

$5 \quad$ Okano $^{1}$, Tomoaki Okuda ${ }^{3}$, Daiki Shishido ${ }^{3}$, Yoshihiro Terui ${ }^{3}$, Shuichi Hasegawa ${ }^{4}$, Takayuki

6 Kameda $^{5}$, Susumu Tohno ${ }^{5}$, Masahiko Hayashi ${ }^{6}$, Chiharu Nishita-Hara ${ }^{6}$, Keiichiro Hara ${ }^{6}$,

$7 \quad$ Kozo Inoue ${ }^{7}$, Yasuda Makoto $^{2}$, Shigeru Hirano ${ }^{2}$, Hirohisa Takano ${ }^{1}$

$8{ }^{1}$ Environmental Health Division, Department of Environmental Engineering, Graduate

9 School of Engineering, Kyoto University, Kyoto, Japan

$10 \quad{ }^{2}$ Department of Otolaryngology-Head and Neck Surgery, Kyoto Prefectural University of

11 Medicine, Kyoto, Japan

$12{ }^{3}$ Faculty of Science and Technology, Keio University, Kanagawa, Japan

$13{ }^{4}$ Center for Environmental Science in Saitama, Japan

$14 \quad{ }^{5}$ Graduate School of Energy Science, Kyoto University, Japan

$15{ }^{6}$ Fukuoka Institute of Atmospheric Environment and Health, Fukuoka University, Japan

$16 \quad{ }^{7}$ Tokyo Dylec Corp, Japan

17

*Corresponding author: Dr. Akiko Honda, Environmental Health Division, Department of

19 Environmental Engineering, Graduate School of Engineering, Kyoto University. C Cluster,

20 Katsura Campus, Nishikyo-ku, Kyoto 615-8540, Japan.

21 Tel.: +81-75-383-3345; Fax: +81-75-383-3344

22 E-mail: akko@health.env.kyoto-u.ac.jp 


\section{Abstract}

25 Ambient particulate matter (PM) epidemiologically exacerbates respiratory and immune health, including allergic rhinitis (AR) and bronchial asthma (BA). Although fine and coarse particles can affect respiratory tract, the differences in their effects on the upper and lower respiratory tract and immune system, their underlying mechanism, and the components responsible for the adverse health effects have not been yet completely elucidated. In this study, ambient fine and coarse particles were collected at three different locations in Japan by cyclone technique. Both particles collected at all locations decreased the viability of nasal epithelial cells and antigen presenting cells (APCs), increased the production of IL-6, IL-8, and IL-1 $\beta$ from bronchial epithelial cells and APCs, and induced expression of dendritic and epithelial cell (DEC) 205 on APCs. Differences in inflammatory responses, but not in cytotoxicity, were shown between both particles, and among three locations. Some components such as $\mathrm{Ti}, \mathrm{Co}, \mathrm{Zn}, \mathrm{Pb}$, As, OC (organic carbon) and EC (elemental carbon) showed significant correlations to inflammatory responses or cytotoxicity. These results suggest that ambient fine and coarse particles differently affect nasal and bronchial epithelial

39 cells and immune response, which may depend on particles size diameter, chemical composition and source related particles types.

42 Keywords: ambient particulate matter, cyclone technique, respiratory cells, immune cells, 43 inflammatory responses

44 Capsule: We showed for the first time in the world that ambient fine and coarse particles 
45 collected from Japan by the new technique using cyclone have different effects on the epithelium cells of the upper and lower respiratory tract and elicit varying immune response, which may depend on particles size diameter, chemical composition and source related particles types.

\section{Introduction}

The health effect of ambient particulate matter (PM) is still a problem worldwide. PM is a complex mixture of particles having different chemical components such as solid and liquid materials that contain elemental carbon (EC), organic carbon (OC), inorganic salts, and metals and biological components such as endotoxin and $\beta$-glucan and has a compound effect on biological reactions (Schins et al., 2004; Cachon et al., 2014; Honda et al., 2017). Generally, the fine fraction of PM (aerodynamic diameter $<2.5 \mu \mathrm{m}$ ) in urban atmosphere is a complex mixture of primary particles emitted from combustion sources and secondary particles that form in the atmosphere from gaseous components (Marcazzan et al., 2001; Sharma et al., 2007; Sevastyanova et al., 2008; Zerbi et al., 2008). The coarse fraction of PM (aerodynamic diameter $>2.5 \mu \mathrm{m}$ ) generally includes mineral particles of crustal material, sea salt particles, fly ash, and adsorbed species such as endotoxin (Schins et al., 2004; Perez et al., 2007). These components can differ depending on the sources, geographical areas, and seasons. In addition, PM composition depends on factors such as atmospheric photochemical reaction and physical redistribution (Vecchi et al., 2004; Samoli et al., 2008).

PM epidemiologically exacerbates respiratory and immune health such as allergic rhinitis (AR) and bronchial asthma (BA) (Tecer et al., 2008) in addition to cardiovascular diseases 
67 and cancer (Kappos et al., 2004). Clinically, AR and BA have a close relationship: about 80\%

68 of patients with BA have complications of AR (Bachert et al., 2002). In general, coarse

69 particles and limited fine particles can affect upper respiratory tract, whereas fine particles

70 and limited coarse particles can affect lower respiratory tract (Heyder J., 1986). However, the

71 difference in the effects of fine and coarse particles on the upper or lower respiratory tract

72 and immune responses related to them, as well as their underlying mechanisms have not yet

73 been clarified. Moreover, the components of PM responsible for the adverse health effects

74 have not yet been elucidated owing to their complexity (Lindbom et al., 2006; Hong et al., 75 2016).

76 A large amount of fine and coarse particles is needed to evaluate the adverse health effects

77 by in vivo and/or in vitro studies. However, it is difficult to collect a sufficient amount of PM

78 by conventional filter collection method with extraction. Because of different extraction

79 efficiency and loss of PM constituents, the exposure experiment using PM extracts has a

80 possibility that would not reflect the actual biological response. Our previous study disclosed

81 extracts efficiency of PM2.5 and discussed the problem (Chowdhury et al., 2018). On the

82 other hand, the cyclone technique enables collection of a sufficient amount of PM (fine and

83 coarse particles themselves) for in vivo and/or in vitro assays enabling the analysis of the

84 effects of ambient particles on respiratory health without the use of a filter or extraction

85 process (Okuda et al., 2015, 2018).

86 In this study, we investigated the effects of ambient fine and coarse particles collected at

87 three Japanese locations by cyclone technique on nasal epithelial cells (RPMI-2650),

88 bronchial epithelial cells (BEAS-2B), and bone marrow derived antigen presenting cells 
89 (APCs) from NC/Nga mice. Our aim was to estimate the different effects of ambient fine and

90

91

92

93

94

95

96

97

98

99

100

101

102

103

104

105

106 coarse particles on respiratory and immune cells, their underlying mechanism, and the components which can be responsible for the respiratory and immune health such as AR and BA.

\section{Materials and Methods}

\subsection{Sampling of PM}

Samples of fine and coarse particles were collected at an urban area in Fukuoka City, at a suburban of the metropolitan area in Kazo City, Saitama Prefecture (Saitama), and a capital area in Yokohama City in Japan (Suppl. Figure S1) during February to March 2017. The particles as references were obtained by National Institute for Environmental Studies in Japan. One reference (CRM\#8) is ethanol-treated vehicle exhaust particulates (Okamoto., 1987) and another (CRM\#28) is irradiated atmospheric dust collected by a ventilation filter of the building in Beijing (Mori et al., 2008). Okuda (2013) has indicated CRM\#8 consists mainly of fine (or ultrafine) particles, while CRM\#28 consist mainly of coarse particles.

The collection was conducted with a high-volume PM sampler using the virtual impactor and cyclone technique with no filter or extraction process (Okuda et al., 2018). The air flow volume per given time for the inlet (virtual impactor) is $1,300 \mathrm{~L} / \mathrm{min}$. The total volume of air sampled was determined from the measured volumetric flow rate and the sampling time. The mass concentration of particles in the ambient air was computed as the total mass of collected particles divided by the total volume of air sampled. After sampling, the particles in the amber bottles were collected using a stainless spatula. We previously confirmed size distribution 
111 and morphology of ambient particles collected by cyclone (Suppl. Figure S2). Particles were

112 dissolved in sterile phosphate-buffered saline (PBS) and ultrasonicated at the concentration

113 of $10 \mathrm{mg} / \mathrm{mL}$. Finally, we adjusted at concentrations of $0,7.5$, and $75 \mu \mathrm{g} / \mathrm{mL}$ using medium,

114 PBS (1\%) and Dimethyl sulfoxide (DMSO) (0.1\%) for the cell exposure experiment in this

115 study. Medium for BEAS-2B cells is serum-free. Similarly, we did not add serum in medium

116 for RPMI-2650 cells to evaluate under the same condition of exposure.

\subsection{Chemical, mineralogical and biochemical investigation}

119 The collected particles was characterized by ion chromatography for Aion species $\left(\mathrm{Cl}^{-}, \mathrm{NO}_{3}{ }^{-}\right.$, 120 and $\left.\mathrm{SO}_{4}{ }^{2-}\right)$ and cation species $\left(\mathrm{Na}^{+}, \mathrm{NH}_{4}{ }^{+}, \mathrm{K}^{+}, \mathrm{Mg}^{2+}\right.$, and $\left.\mathrm{Ca}^{2+}\right)$, thermal-optical method 121 (IMPROVE protocol) for OC1-4 and EC1-3, high performance liquid chromatography 122 (HPLC) for polycyclic aromatic hydrocarbons (PAHs) (Chrysene, Benz[a]anthracene, 123 Benzo[b]fluoranthene, Benzo[k]fluoranthene, and Benzo[a]pyrene), and inductively coupled 124 plasma mass spectrometry (ICP-MS) for metals (Al, Si, Ti, V, Cr, Mn, Fe, Ni, Cu, Zn and $125 \mathrm{~Pb}$ ). The procedure of chemical characterization mentioned above were generally described 126 in several previous papers (Okuda., 2013; Okuda et al., 2013, 2014). Endotoxin and $\beta$-glucan 127 have induced inflammatory responses from respiratory cells and immune cells (Veranth et al., 128 2004; Carmona et al., 2010; Neveu et al., 2011). In this study, we investigated the effect of 129 endotoxin and $\beta$-glucan as substances derived from biological components in PM. We 130 performed an endotoxin test and a $\beta$-glucan test (both from Associates of Cape Cod, 131 Falmouth, MA, USA) following the manufacturer's instructions. 
133

134

135

136

\subsection{Cell Cultures and PM exposure}

\subsubsection{Upper and Lower Respiratory cells}

The RPMI-2650, derived from squamous cell carcinoma of nasal septum was used as model of human nasal epithelial cells which are cells of the upper respiratory tract. These cells display consistent growth and high stability throughout continued culturing in vitro with no alteration to the normal diploid karyotype (Moorhead, 1965). The cell line was purchased from the European Collection of Cell Cultures (Salisbury, Wiltshire, United Kingdom) and maintained in Eagle’s minimal essential medium (DS Pharma Biomedicals, Osaka, Japan) supplemented with 10\% heat-inactivated fetal bovine serum (MP Biomedicals, Eschwege, Germany), 2 mM L-glutamine, $100 \mathrm{U} / \mathrm{mL}$ penicillin and $100 \mu \mathrm{g} / \mathrm{mL}$ streptomycin (Sigma, St Louis, Missouri). As representative of the cells of the lower respiratory tract, the BEAS-2B, derived from human bronchial epithelial cells, was purchased from the European Collection of Cell Cultures and maintained in LHC-9 medium (Thermo Scientific, Waltham, Massachusetts) which is serum-free medium containing Gentamicin. RPMI-2650 cells and BEAS-2B cells were maintained by subculture in $37^{\circ} \mathrm{C}$ at $5 \% \mathrm{CO}_{2}$ in medium.

\subsubsection{Immune cells}

Ten-week-old male SPF NC/NgaTndCrlj mice were purchased from Charles River (Osaka, Japan). NC/Nga mice are atopy-prone mice. APCs were obtained after sacrificing mice by cervical dislocation and exsanguination. The procedures used in all animal studies were approved by the Animal Research Committee at Kyoto University. APCs were differentiated using a modification of the protocol provided by Lutz et al (1999). We confirmed APCs by 
155 the expression of about $80 \%$ of CD11c which is a molecule specifically expressed in dendritic 156 cells. Bone marrow cells $\left(4 \times 10^{5} / \mathrm{mL}\right)$ were cultured in R10 which is RPMI 1640 (Thermo

157 Scientific) supplemented with 10\% heat-inactivated fetal bovine serum (MP Biomedicals), $158100 \mathrm{U} / \mathrm{mL}$ penicillin, $100 \mu \mathrm{g} / \mathrm{mL}$ streptomycin (Sigma), and $50 \mathrm{mM}$ 2-mercaptoethanol 159 (Thermo Scientific) containing Granulocyte-Macrophage Colony-Stimulating Factor (GM$160 \mathrm{CSF})$.

\subsection{Experimental Protocol}

163 The RPMI-2650 cells, BEAS-2B cells, and APCs were exposed to ambient fine and coarse 164 particles at concentrations of $0,7.5$, or $75 \mu \mathrm{g} / \mathrm{mL}$ and reference particles at $75 \mu \mathrm{g} / \mathrm{mL}$ only 165 for $24 \mathrm{~h}$. We evaluated the cell viability, the cytokine release, and dendritic and epithelial 166 cell (DEC) 205 on the cell surface. All control cells were treated with each medium.

\subsubsection{Cell Viability}

169 We measured the viability of the RPMI-2650 cells, BEAS-2B cells, and APCs by WST-1 170 assay using the Premix WST-1 Cell Proliferation Assay System (TaKaRa Bio, Shiga, Japan) 171 as previously described (Honda et al., 2017). The results are expressed as the percentage of 172 exposed group to control cells $(0 \mu \mathrm{g} / \mathrm{mL})$.

\subsubsection{Quantification of Pro-Inflammatory Cytokines in the Culture Supernatants}

175 The amounts of IL-6 and IL-8 release in the supernatants from the RPMI-2650 cells and 176 BEAS-2B cells and those of IL-6 and IL-1 $\beta$ release in the supernatants from APCs were 
177 measured by ELISA (Thermo Scientific), according to the manufacturer's protocol as 178 previously described (Honda et al., 2017). The detection limits of IL-6 and IL-8 from RPMI1792650 cells and BEAS-2B cells, and IL-6 and IL-1 $\beta$ from APCs were $<2.2 \mathrm{pg} / \mathrm{mL},<9.8 \mathrm{pg} / \mathrm{mL}$, $180<1.9 \mathrm{pg} / \mathrm{mL},<1.6 \mathrm{pg} / \mathrm{mL},<16 \mathrm{pg} / \mathrm{mL}$ and $10 \mathrm{pg} / \mathrm{mL}$, respectively.

\subsubsection{Expression of DEC205 on APCs cell surface}

183 We measured the expression of DEC205 on the APCs' surface by the FACS analysis, the 184 following monoclonal antibodies were used: Mouse BD Fc Block purified anti-mouse 185 CD16/CD32 (Becton Dickinson), DEC205 (NLDC-145, PE-conjugated; Bio-Legend, San 186 Diego, California), Rat IgG2a, k Isotype Control (RTK2758, PE-conjugated; BioLegend). 187 The fluorescence was measured by a FACSCalibur (Becton Dickinson) as previously 188 described (Honda et al., 2017).

\subsection{Statistical Analysis}

191 The data are presented as the mean \pm standard error of the mean (SEM) for each experimental 192 group ( $\mathrm{n}=3$ or 4 ). The significance of variation among different groups was determined by 193 one-way analysis of variance. Differences among groups were analyzed using Tukey’s 194 multiple comparison test. A P-value < 0.05 was considered to indicate a significant difference. 195 Relationships between components in PM and cell viability or cytokine release were tested 196 using Pearson's correlation, with a two-tailed significance study using SPSS software. A P < 1970.01 and $\mathrm{R}>0.9$ was shown as a high degree of correlation. 
199

200

201

202

203

204

205

206

207

208

209

210

211

212

213

214

215

216

217

218

219

220

\section{Results}

\subsection{The characterization of collected ambient particles}

This cyclone system achieved 50\% collection efficiency with components having the following aerodynamic cut-off diameters: virtual impactor, $2.4 \mu \mathrm{m}$; fine-particle cyclone, 0.18-0.30 $\mu \mathrm{m}$; and coarse-particle cyclone, $0.7 \mu \mathrm{m}$. Particles smaller than $2.4 \mu \mathrm{m}$ flowed to the fine side at the virtual impactor part, and thus, fine particles were $0.30-2.4 \mu \mathrm{m}$ and coarse particles were $2.4 \mu \mathrm{m}$ or more in size. The mean concentrations of fine particles in Fukuoka, Saitama, and Yokohama were 3.0, 5.9 and $9.9 \mu \mathrm{g} / \mathrm{m}^{3}$, respectively while those of coarse particles were $1.5,4.3$ and $14.2 \mu \mathrm{g} / \mathrm{m}^{3}$, respectively. Note that these mass concentrations of fine and coarse particles were expressed as the weights of particles collected by the cyclones per sampled air volume. The concentrations of components of both particles in the prepared solution are shown (Suppl. Table S1-S3). Both particles had different proportions of metal components between Fukuoka and the other locations. In Fukuoka, instead of a small amount of metal components, amounts of $\mathrm{Na}^{+}, \mathrm{Cl}^{-}$and $\mathrm{SO}_{4}{ }^{2-}$ were high (Suppl. Figure S3).

The content of endotoxin in fine and coarse particles was 0.080 and 0.060 (Fukuoka), 2.50 and 2.97 (Saitama), 4.29 and 6.59 (Yokohama) EU/mL, respectively. Endotoxin in both particles at Fukuoka was lower than those collected at Saitama and Yokohama. The highest content of endotoxin was found in coarse particles at Yokohama. The contents of $\beta$-glucan in fine and coarse particles were 317.3 and 1106 (Fukuoka), 294.4 and 666.0 (Saitama), 774.6 and 1060 (Yokohama) pg/mL, respectively. $\beta$-glucan in fine particles collected at all locations was lower than those in coarse particles at each location. The highest content of $\beta$ glucan was present in coarse particles at Fukuoka. 


\subsection{Biological effects of ambient particles on the Nasal Epithelial Cells}

223 We examined the effects of exposure (24 h) to ambient fine and coarse particles on the 224 viability of RPMI-2650 cells. A significant decrease ( $p<0.01$ vs. control) in the viability of 225 cells was seen upon exposure to both particles collected at all locations in a concentration226 dependent manner as compared to the control (unexposed cells). No difference in cytotoxicity 227 caused by ambient fine and coarse particles from each location was detected except for 228 sample collected at Yokohama at a concentration of $7.5 \mu \mathrm{g} / \mathrm{mL}$ (Figure 1).

229 We investigated the effects of $24 \mathrm{~h}$ exposure of ambient fine and coarse particles on the pro230 inflammatory responses via release of IL-6 and IL-8 from RPMI-2650 cells. None of the 231 particles, at any location were able to evoke detectable cytokine release from RPMI-2650 232 cells.

\subsection{Biological effects of ambient particles on the Bronchial Epithelial Cells}

235 We examined the effects of exposure to ambient fine and coarse particles for $24 \mathrm{~h}$ on the 236 viability of BEAS-2B cells. BEAS-2B cells showed no decrease in viability upon exposure 237 to both particles collected at all locations at any concentration, when compared to control 238 (unexposed cells) (Figure 2A).

239 We investigated the effects of ambient fine and coarse particles on the pro-inflammatory 240 responses via release of IL-6 and IL-8 from BEAS-2B cells after exposure to each particle

241 for 24 h. Both particles collected at all locations increased IL-6 release, in a dose-dependent 242 manner, especially at the concentration of $75 \mu \mathrm{g} / \mathrm{mL}$ (Figure 2B; $\mathrm{p}<0.01$ vs. control). 
243 Comparison between fine and coarse particles at the same location indicated that coarse 244 particles at Fukuoka induced higher production of IL-6 than fine particles (Figure 2B; p < 2450.01 vs. fine particles at $75 \mu \mathrm{g} / \mathrm{mL}$ ). Comparison among the three locations indicated that 246 fine particles collected at Saitama or Yokohama had greater effect than those at Fukuoka 247 (Figure 2B; $\mathrm{p}<0.01$ vs. fine particles at Fukuoka at $75 \mu \mathrm{g} / \mathrm{mL}$ ). Coarse particles collected at 248 Fukuoka had significantly larger effect than those collected at Saitama (Figure 2B; p $<0.05$ vs. coarse particles at Fukuoka at $75 \mu \mathrm{g} / \mathrm{mL}$ ). The production of IL-8 showed a pattern similar 250 to that of IL-6. The results of IL-8 different from IL-6 are shown. Coarse particles collected 251 at Fukuoka, fine particles collected at Saitama and both particles collected at Yokohama 252 significantly increased the levels of IL-8 at a concentration of $7.5 \mu \mathrm{g} / \mathrm{mL}$ (Figure $2 \mathrm{~B} ; \mathrm{p}<0.05$ 253 or 0.01 vs. control). The fine particles collected at Yokohama showed significantly marked 254 induction of IL-8 than coarse particles (Figure 2B; $\mathrm{p}<0.05$ vs. fine particles at $75 \mu \mathrm{g} / \mathrm{mL}$ ). 255 Fine particles collected at Yokohama had greater effect than those collected at Saitama 256 (Figure 2B; $\mathrm{p}<0.01$ vs. fine particles at Saitama at $75 \mu \mathrm{g} / \mathrm{mL}$ ).

\subsection{Biological effects of ambient particles on the APCs}

259 We examined the effects of ambient fine and coarse particles on the viability of APCs after 260 exposure to PM for $24 \mathrm{~h}$. Exposure to both particles resulted in decrease in viability of APCs

261 in a dose-dependent manner as compared to control (unexposed cells) (Figure 3A). A 262 significant decrease in the viability of cells was seen upon exposure to both particles collected 263 at all locations at a concentration of $75 \mu \mathrm{g} / \mathrm{mL}$ and for those at Saitama and Yokohama at the 264 concentration of $7.5 \mu \mathrm{g} / \mathrm{mL}$ (Figure 3A; p $<0.05$ or 0.01 vs. control). Coarse particles 
265 collected at Fukuoka slightly decreased the viability of cells at a concentration of $7.5 \mu \mathrm{g} / \mathrm{mL}$

266 (Figure 3A; $\mathrm{p}<0.05$ vs. control). No difference in cytotoxicity was detected between fine 267 and coarse particles collected at each location.

268 We investigated the effects of ambient fine and coarse particles on the pro-inflammatory 269 responses analyzed as IL-6 and IL-1 $\beta$ released from APCs after exposure to each particle for 27024 h. Both particles collected at all locations increased IL-6 release in a dose-dependent 271 manner especially at a concentration of $75 \mu \mathrm{g} / \mathrm{mL}$ (Figure 3B; $\mathrm{p}<0.01$ vs. control). Both 272 particles collected at Saitama and Yokohama also significantly increased the levels of IL-6 273 at the concentration of $7.5 \mu \mathrm{g} / \mathrm{mL}$ (Figure 3B; $\mathrm{p}<0.01 \mathrm{vs.} \mathrm{control).} \mathrm{Coarse} \mathrm{particles} \mathrm{collected}$ 274 at Fukuoka induced higher production of IL-6 than the fine particles (Figure 3B; $\mathrm{p}<0.01$ vs. 275 fine particles at $75 \mu \mathrm{g} / \mathrm{mL}$ ). Both particles collected at Saitama and Yokohama induced higher 276 production of IL-6 than that collected at Fukuoka (Figure 3B; $\mathrm{p}<0.05$ or 0.01 vs. fine 277 particles at Fukuoka at 7.5 and $75 \mu \mathrm{g} / \mathrm{mL}$ ). Both particles at all locations increased IL-1 $\beta$ 278 release, in a dose -dependent manner, especially at the concentration of $75 \mu \mathrm{g} / \mathrm{mL}$ similar to 279 what was observed in case of IL-6 (Figure 3B; $\mathrm{p}<0.01$ vs. control). Coarse particles collected 280 at Saitama and both particles at Yokohama at a concentration of $7.5 \mu \mathrm{g} / \mathrm{mL}$ increased the 281 levels of IL-1 $\beta$ (Fig 3B; p < 0.05 or 0.01 vs. control). Coarse particles collected at Fukuoka 282 induced lower production of IL-1 $\beta$ than the fine particles (Figure 3B; $\mathrm{p}<0.05$ vs. fine 283 particles at $75 \mu \mathrm{g} / \mathrm{mL}$ ). Both particles at Fukuoka resulted in greater induction of IL-1 $\beta$ than 284 those at Saitama and Yokohama (Figure 3B; p < 0.05 or 0.01 vs. both particles at Fukuoka at $28575 \mu \mathrm{g} / \mathrm{mL}$, respectively).

286 The expression patterns of DEC205 in APCs were examined in order to evaluate the effects 
287 of exposure to ambient fine and coarse particles for $24 \mathrm{~h}$ on the maturation and activation of 288 APCs. DEC205 is a member of the macrophage mannose receptor family. This molecule is 289 known to mediate the capture and internalization of ligands for subsequent processing and 290 presentation by APCs (Jiang et al., 1995). Both particles collected at all locations increased 291 the ratio of DEC205-positive cells at concentrations of 7.5 and $75 \mu \mathrm{g} / \mathrm{mL}$ (Figure 3C; p < 2920.01 vs. control). Although, there were no significant differences in the ratio of DEC205293 positive cells exposed to the both particles collected at the same location, fine particles 294 collected at Yokohama significantly increased the ratio of DEC205-positive cells when 295 compared with those at Fukuoka (Figure 3C; p $<0.05$ vs. fine particles at Fukuoka at 7.5 $296 \mu \mathrm{g} / \mathrm{mL})$.

\subsection{Correlation between ambient particles components and biological responses}

299 Determination of the PM components responsible for impacts on examined cell lines by 300 assessing cytotoxicity, pro-inflammatory cytokine release is very important. We evaluated 301 Pearson's correlation coefficients between both particles compounds and the cell viability of 302 RPMI-2650 cells and APCs, and both particles compounds and cytokine release from BEAS303 2B cells and APCs. Our analysis showed negative correlations between the cell viability of 304 RPMI-2650 cells and $\mathrm{Ca}^{2+}$, Zn, and OC (Suppl. Figure S4). Positive correlations were 305 observed between IL-6 and IL-8 release from BEAS-2B cells and IL-6 release from APCs 306 and multiple components, including EC, OC, and metals such as Ti and Co (Suppl. Figure 307 S5, S6A). Whereas, positive correlations between IL-1 $\beta$ from APCs and multiple 308 components, including ions, EC, OC, and metals such as As and Pb were shown (Suppl. 
309 Figure S6B).

\section{4. Discussion}

312 In the present study, we conducted experiments using ambient fine and coarse particles 313 collected by cyclone technique. Ambient both particles decreased the cell viability of RPMI3142650 cells and APCs, and induced production of pro-inflammatory cytokines from BEAS315 2B cells and APCs. There was a significant difference in the inflammatory response elicited 316 by fine and coarse particles at Fukuoka. Inflammatory responses induced by particles 317 collected at Saitama and Yokohama were similar to each other but different from those 318 observed for particles collected at Fukuoka. Ambient both particles also induced expression 319 of DEC205 on APCs. Viability of RPMI-2650 cells correlated negatively with $\mathrm{Ca}^{2+}$, Zn, and 320 OC3 and OC4. IL-6 and IL-8 release correlated positively with Ti, Fe, Co, Cr, Mn, V, and Zn, 321 and OC3, OC4, and EC2, whereas IL-1 $\beta$ release correlated positively with As, Pb, and OC2 322 and EC1.

323 Ambient both particles at all locations decreased viability of RPMI-2650 cells but did not 324 induce pro-inflammatory cytokines. Nasal epithelial cells are the first epithelial barrier in the 325 nasal cavity imparting protection from inhaled xenobiotics. Previous studies have indicated 326 that diesel exhaust particles (DEP) or PM10 do not show cytotoxicity nor induce production 327 of pro-inflammatory cytokines from RPMI-2650 cells (Lindbom et al., 2006) and that DEP 328 does not reduce cell viability but decrease the barrier function by reducing zonula occludens 329 -1 (ZO-1) expression in RPMI-2650 cells (Fukuoka et al., 2015). If the barrier function 330 decreases even without cytotoxicity, there is a possibility that PM further weaken the barrier 
331 function due to cytotoxicity. It is possible that particles collected in this study weakened the 332 barrier function, thereby allowing easy invasion by allergens.

333 It has been reported that primary nasal epithelial cells have lesser Toll-like receptor (TLR) 334 expression compared to alveolar epithelial cells, and more distribution of Toll-interacting 335 protein (TOLLIP; an inhibitor of TLR signaling) which may be one of the reasons for non336 induction of pro-inflammatory cytokines by these cells (Moncayo et al., 2014). The low 337 inflammatory responses due to the low expression of TLR and the high expression of 338 TOLLIP on nasal epithelial cells may lead to colonization and coexistence of many resident 339 bacterial groups in the nasal cavity environment. The epithelial cells in the nasal cavity are 340 always exposed to external environment and various bacteria or chemicals therein. Hence, 341 tolerance to these bacteria without induction of inflammation is required to maintain 342 homeostasis.

343 In case of BEAS-2B cells, though ambient both particles at all locations elevated the levels 344 of IL-6 and IL-8 release, none of them decreased the cell viability. Ambient both particles 345 strongly induced pro-inflammatory cytokine production compared to both reference particles. 346 Bronchial epithelial cells also act as a physical barrier and generate biological and 347 immunological responses against inhaled xenobiotics. IL-6 and IL-8 are the major pro348 inflammatory cytokines induced by response to environmental insults and are important key 349 molecules causing acute inflammation in the respiratory system by stimulating lymphocytes 350 (Thacker, 2006). Previous studies have indicated that various chemicals and allergens 351 stimulate IL-6 or IL-8 production from BEAS-2B cells (Honda et al., 2014; Totlandsdal et 352 al., 2012; Park et al.,2009). Ambient both particles collected by cyclone technique can 
353 exacerbate allergic inflammation by inducing inflammatory cytokines.

354 Extracts from PM on filter have been used for experiments dealing with health effects of PM.

355 To our knowledge, this is the first experimental demonstration of the effects of allergic

356 inflammation by ambient fine and coarse particles collected by cyclone technique.

357 Fuentes-Mattei et al. (2010) have showed that PM2.5 organic extracts from urban area in

358 Puerto Rico at $50 \mu \mathrm{g} / \mathrm{mL}$ decrease about $20 \%$ of cell viability and produce about $650 \mathrm{pg} / \mathrm{mL}$ 359 of IL-6 and $235 \mathrm{pg} / \mathrm{mL}$ of IL-8 from BEAS-2Bcells, but those from rural area do not decrease 360 cell viability and induce the lower production of IL-6 compared to those from urban area. 361 Gualtieri et al. (2010) have showed that PM2.5 and PM10 aqueous extracts from urban area 362 in Milan at $10 \mu \mathrm{g} / \mathrm{cm}^{2}$ (in this study, $75 \mu \mathrm{g} / \mathrm{mL}=13.7 \mu \mathrm{g} / \mathrm{cm}^{2}$ ) do not decrease cell viability 363 and produce about $80 \mathrm{pg} / \mathrm{mL}$ and $400 \mathrm{pg} / \mathrm{mL}$ of IL-8 from BEAS-2B, respectively. We have 364 previously indicated that exposure to PM2.5 collected in winter and subjected to organic 365 extraction rather than aqueous extraction causes an inflammatory response via IL-6 366 production from bronchial epithelial cells and PM2.5 extracts at Fukuoka subjected to 367 organic extraction, produced about $110 \mathrm{pg} / \mathrm{mL}$ of IL-6 at a concentration of $75 \mu \mathrm{g} / \mathrm{mL}$ which 368 was about 2 times greater than the level of control (Honda et al., 2017). These same extracts 369 collected in another season produced about $15 \mathrm{pg} / \mathrm{mL}$ of IL-6 and about $200 \mathrm{pg} / \mathrm{mL}$ of IL-8 370 from bronchial epithelial cells, and the levels of these cytokines were less than control 371 (Chowdhury et al., 2018). In the present experiment, fine particles collected by cyclone 372 technique at Fukuoka at $75 \mu \mathrm{g} / \mathrm{mL}$ produced about $250 \mathrm{pg} / \mathrm{mL}$ of IL-6 and about $670 \mathrm{pg} / \mathrm{mL}$ 373 of IL-8 in BEAS-2B cells. The levels of IL-6 and IL-8 produced by fine particles collected 374 using cyclone technique was about 6 and 2.5 times more than the level of control, respectively. 
375 Although we could not strictly compare these results because it is not exactly the same 376 particle, it is suggested that ambient particles collected by cyclone technique could induce 377 larger inflammatory response than that induced by PM collected by the conventional filter 378 technique with extraction. Cyclone technique is an efficient method for collecting particles 379 that are subjected to exposure studies. Currently, there exist only a few assessments of health 380 effect conducted using ambient particles collected by cyclone technique and hence, further 381 research in this area should be encouraged (Ogino et al., 2017).

382 In the present study, ambient both particles collected at all locations induced expression of 383 DEC205 on APCs. The current study is the first report that ambient particles collected by 384 cyclone technique activates APCs via DEC205 expression. Several studies have shown that 385 carbon black nanoparticles and Asian dust particles can promote the maturation/activation 386 and function of DEC205 on APCs and may be related to their enhancing effects on allergic 387 diseases or responses (Honda et al., 2014; Koike et al., 2008). Ambient both particles induced 388 pro-inflammatory cytokines such as IL-6 and IL-1 $\beta$ from APCs as well as BEAS-2B cells. 389 Ambient both particles strongly induced pro-inflammatory cytokine production compared to 390 both reference particles. IL-1 $\beta$ has been described as a potent pro-inflammatory cytokine and 391 a mediator of a wide range of systemic human diseases (Dinarello, 2005; Koh et al., 2006; 392 Allantaz et al., 2007; James et al., 2011). The difference in reaction of IL-6 and IL-1 $\beta$ 393 observed in this study may be due to the difference in the transcription factors of cytokines 394 or in the sensitivity to exposure components. APCs play important roles in allergens-related 395 airway inflammation (Lambrecht et al., 2012). APCs are activated upon invasion of the upper 396 or lower respiratory tract by ambient particles collected by cyclone technique. As a result, 
397 ambient particles can affect allergic inflammation not only by induction DEC205 expression, 398 but also through induction of pro-inflammatory cytokines.

399 Some experimental and epidemiological studies have indicated that PM10 may exhibit a 400 similar or higher pro-inflammatory potential than PM2.5 and lead to adverse pulmonary 401 responses, which may require hospitalization (Monn et al., 1999; Becker et al., 2005; 402 Brunekreef et al., 2005; Gerlofs et al., 2007; Camatini et al., 2008). One of the reasons for 403 this may be attributed to the greater presence of microbial factors such as endotoxins or $\beta$ 404 glucan in PM10 as compared to PM2.5. Previous studies have shown endotoxin and $\beta$-glucan 405 to be associated with the inflammatory effects of PM both in in vitro and in vivo (Douwes et 406 al., 2003; Becker et al., 2005; Jalava et al., 2008). The U.S. Environmental Protection Agency 407 (1995) has noted that PM10 deposits in the upper airways of the lungs and may be more 408 relevant for asthmatic responses and irritation. On the other hand, PM2.5 is more often the 409 cause of lower respiratory symptoms such as cough and sputum compared to PM10 410 (Schwartz et al., 2000). In this way, although both PM can cause harmful health effects, the 411 one that causes greater harm has not been elucidated. In the present study, almost no 412 difference of cytotoxicity on RPMI-2650 cells and APCs was observed between the fine and 413 coarse particles. However, coarse particles collected at Fukuoka induced higher production 414 of IL-6 and IL-8 from BEAS-2B cells and IL-6 from APCs than fine particles, but lesser 415 production of IL-1 $\beta$ from APCs. Fine particles collected at Yokohama induced higher 416 production of IL-8 from BEAS-2B cells than coarse particles. Our analysis did not show 417 strong correlations between pro-inflammatory cytokine release and microbial factors. 418 Previous studies have suggested that endotoxin at $2000 \mathrm{EU} / \mathrm{mL}$ and $\beta$ glucan at the 
419 concentration of " $\mu \mathrm{g} / \mathrm{mL}$ " induces pro-inflammatory responses in airway epithelial cells or 420 APCs (Carmona et al. 2010, Veranth et al. 2004). As the level of endotoxin and $\beta$ glucan in 421 our study was very low compared to those of the previous studies, we suspect that the level 422 of endotoxin and $\beta$ glucan in our study failed to noticeable correlation with inflammation in 423 the cells. Apart from microbial factors, previous studies have suggested that co-exposure of $424 \mathrm{SO}_{4}{ }^{2-}$ or constituent of cedar pollen enhances inflammatory responses (Hiyoshi et al., 2005; 425 Ichinose et al., 2005; Yamada et al., 2012). Not only biological factors but also other 426 compounds contained in PM or allergen substance can contribute to the production of pro427 inflammatory cytokines.

428 Yokohama is the most populated city and located in one of the three major industrial areas in 429 Japan. Saitama is close to Yokohama, and relatively the secondary particle tends to be the 430 main component of the formation of fine particles, so secondary air pollution is considered. 431 (Takegawa et al., 2006; Miyakawa et al., 2008). Yokohama and Saitama are located in 432 urban/suburban and industrial areas, respectively. Fe, Cr, Mn, Zn and Co are emitted by the 433 steel industry and V is mainly emitted by oil combustion (Lin et al., 2005; Querol et al., 2006; 434 Japan Ministry of the Environment, 2014). Titanium originates from the chemical industry 435 dealing with nanomaterial particles such as titanium dioxide (Chao et al., 2011). As these 436 metals in particles were correlated with IL-6 and IL-8 production in Yokohama and Saitama, 437 anthropogenic metals might contribute to respiratory disorders. On the other hand, Fukuoka 438 is closest to Mainland China, therefore there are a possibility that the influence of 439 transboundary pollution from China. (kaneyasu et al.,2014; Takami et al., 2016). It has been 440 reported that $\mathrm{As}$ and $\mathrm{Pb}$ are abundantly contained in coal which is the main energy source in 
441 China (Hioki et al., 2009). Generally, atmospheric concentration of As in Japan is very low, 442 and there are few specific sources of As (Taniguchi et al. 2016). At least, the present study 443 demonstrated that As contained much in the particles in Fukuoka showed a high correlation 444 with IL-1 $\beta$ release. This indicated that Fukuoka may be influenced by transboundary 445 pollution from China. However, the other biological responses induced by the particles 446 collected in Fukuoka was lower than the particles in other locations. Hence, particles caused 447 by transboundary contamination may have lower biological activity than particles having a 448 source in our country.

449 Previous studies have reported that metals and their compounds mentioned above induce IL4506 , IL-8 or IL-1 $\beta$ in vivo and/or in vitro studies. For example, Ti or $\mathrm{CoCl}_{2}$ induce the 451 production of IL-6 or IL-8 from bronchial epithelial cells or human lung microvascular 452 endothelial cells, and IL-1 $\beta$ are induced from alveolar macrophages by intratracheal 453 administration of As in mice (Huaux et al., 1995; Carter et al., 1997; Schmalz et al., 1998; 454 Ming et al., 2000; Pascal et al., 2004; Kyoung et al., 2006; Eun-Jung et al., 2008, 2010). It is 455 possible that metals such as Ti, Fe, Cr, Mn, Co, V, Zn, Pb and As can induce IL-6, IL-8 or 456 IL-1 $\beta$ from BEAS-2B cells and APCs, but further investigation is needed to identify the 457 responsible components. The components in OC and EC have not yet been well elucidated 458 (Grabowsky et al., 2011; Ikemori et al., 2009). However, low- and less- volatile organic 459 carbons (OC3 and OC4) may play an important role in the inflammatory reaction in each cell. 460 Previous studies have reported metals or ions such as Fe, Zn, Cr, Mn, V and $\mathrm{Cu}$ induce 461 toxicity of airway epithelial cells (Riley et al., 2003; Honda A., 2015). The concentrations of 462 Fe, Cr, V and Cu in our study was low compared to those of the previous studies, but Mn and 
463 Zn was equivalent concentrations. In this study, we showed only high correlation between

$464 \mathrm{Zn}$ and toxicity, however it is a possible that the other metals such as Fe, $\mathrm{Cr}, \mathrm{Mn}, \mathrm{V}$ and $\mathrm{Cu}$ 465 also induce toxicity of airway epithelial cells.

\section{Conclusion}

Exposure to ambient particles collected by cyclone technique reduced cellular viability in RPMI-2650 cells and APCs, induced pro-inflammatory responses in BEAS-2B cells and APCs, and induced the maturation/activation of APCs. There was correlation between of some chemical components and biological responses. These chemical components affected differently between nasal and bronchial epithelial cells and elicited varying immune response.
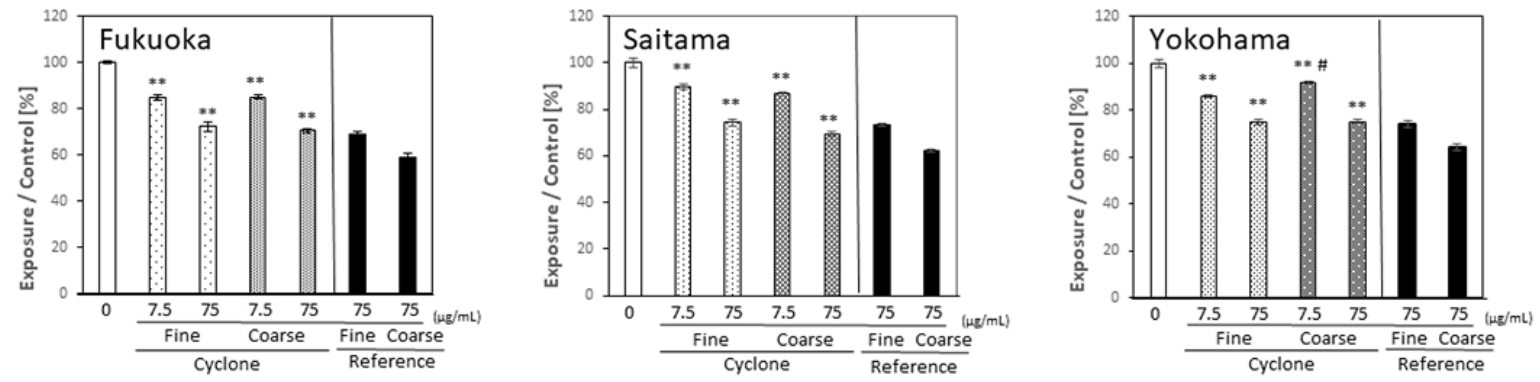

477 Figure 1. Effects of ambient particles and reference particles on the viability of RPMI-2650

478 cells. Data are presented as the percentage of the viability of the control. Data are mean \pm 479 standard error of the mean (SEM) of 4 individual cultures. $* \mathrm{P}<0.05, * * \mathrm{P}<0.01 \mathrm{vs} .0 \mu \mathrm{g} / \mathrm{mL}$, $480 \quad{ }^{\#} \mathrm{P}<0.05$ vs. Fine particles at $7.5 \mu \mathrm{g} / \mathrm{mL}$. 

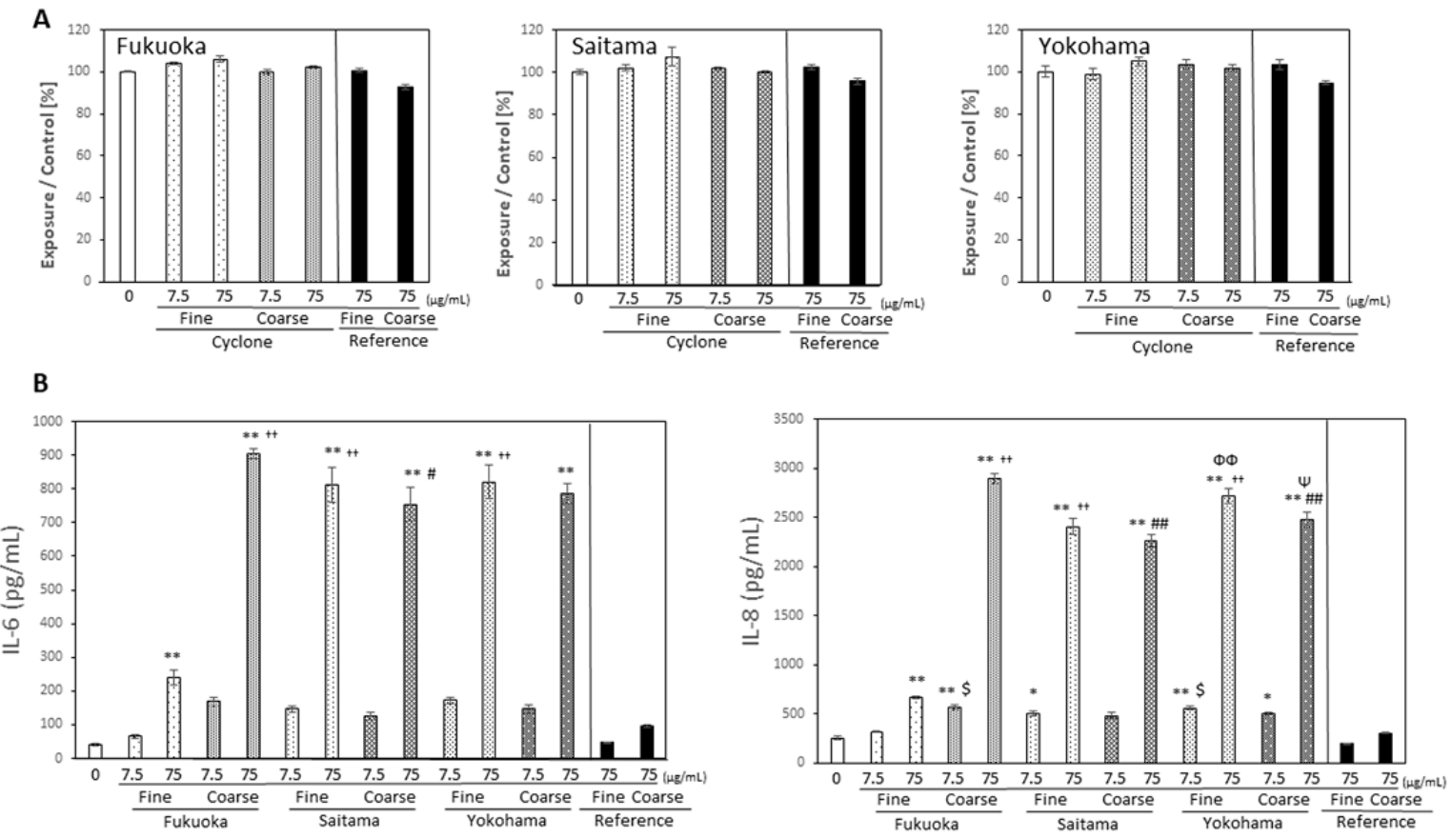

482

Figure 2. (A): Effects of ambient particles and reference particles on the viability of BEAS2B cells. Data are presented as the percentage of the viability of the control. (B): IL-6 and IL-8 production from BEAS-2B cells in response to ambient particles and reference particles. Date are mean \pm standard error of the mean $(\mathrm{SEM})$ of 4 individual cultures. ${ }^{*} \mathrm{P}<0.05$, ${ }^{* *} \mathrm{P}<0.01$ vs. $0 \mu \mathrm{g} / \mathrm{mL},{ }^{\$} \mathrm{P}<0.05$ vs. Fine particles at Fukuoka at $7.5 \mu \mathrm{g} / \mathrm{mL},{ }^{\dagger \dagger} \mathrm{P}<0.01$ vs. Fine particles at Fukuoka at $75 \mu \mathrm{g} / \mathrm{mL},{ }^{\#} \mathrm{P}<0.05,{ }^{\# \#} \mathrm{P}<0.01$ vs. Coarse particles at Fukuoka at 75 $489 \mu \mathrm{g} / \mathrm{mL},{ }^{\Phi \Phi} \mathrm{P}<0.01$ vs. Fine particles at Saitama at $75 \mu \mathrm{g} / \mathrm{mL},{ }^{\Psi} \mathrm{P}<0.05$ vs. Fine particles at 490 Yokohama at $75 \mu \mathrm{g} / \mathrm{mL}$. 

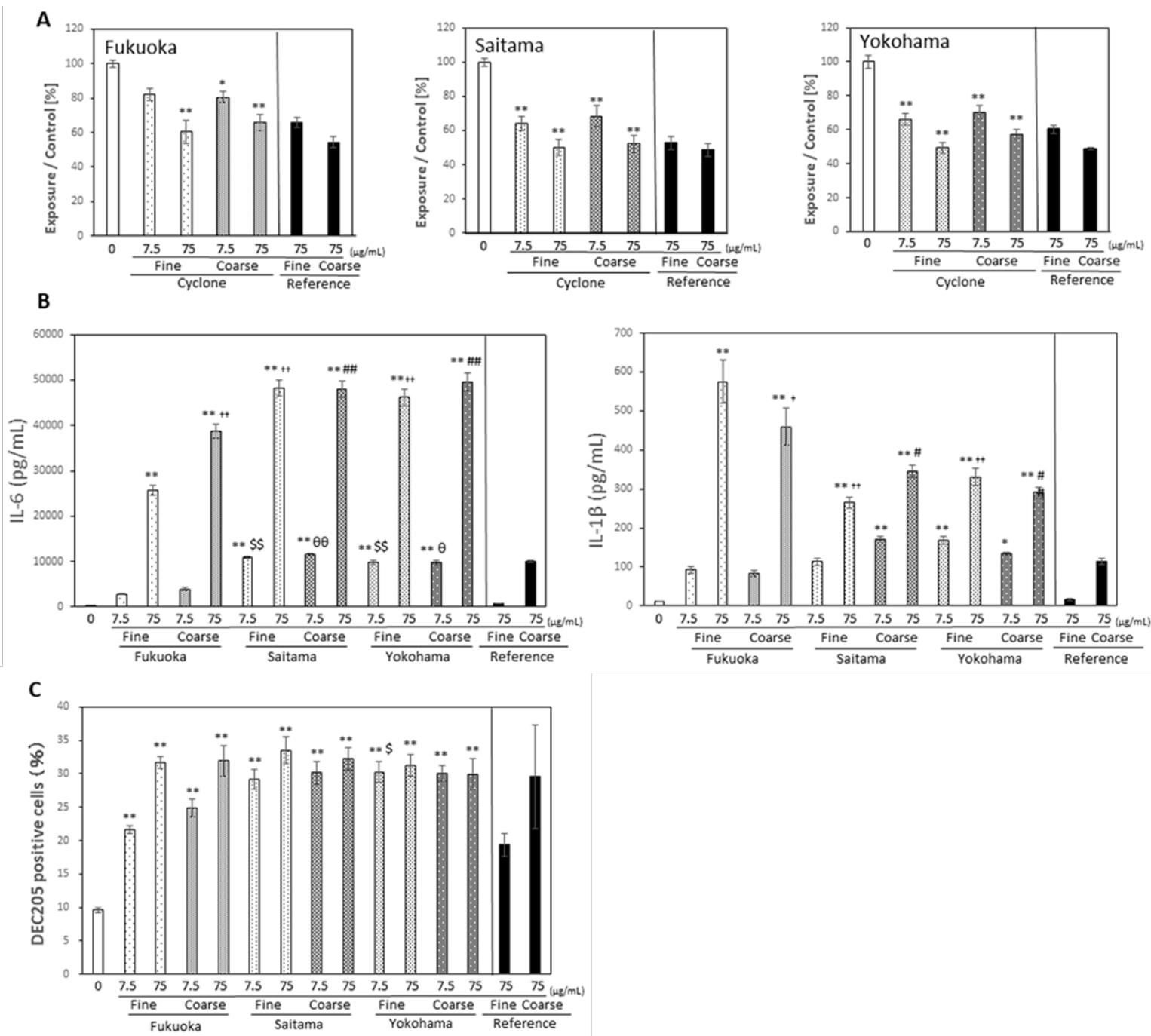

Figure 3. (A): Effects of ambient particles and reference particles on the viability of APCs.

Data are presented as the percentage of the viability of the control. (B):IL-6 and IL-1 $\beta$ production from APCs in response to ambient particles and reference particles. (C): Effects 496 of ambient particles and reference particles on the DEC205 expression of APCs. Date are 497 presented as positive cells expressed \% events. Date are mean \pm standard error of the mean 498 (SEM) of 4 individual cultures. ${ }^{*} \mathrm{P}<0.05,{ }^{*} * \mathrm{P}<0.01$ vs. $0 \mu \mathrm{g} / \mathrm{mL},{ }^{\$} \mathrm{P}<0.05,{ }^{\$} \mathrm{P}<0.01$ vs. Fine 499 particles at Fukuoka at $7.5 \mu \mathrm{g} / \mathrm{mL},{ }^{\dagger} \mathrm{P}<0.05,{ }^{\dagger \dagger} \mathrm{P}<0.01$ vs. Fine particles at Fukuoka at 75 
$500 \mu \mathrm{g} / \mathrm{mL},{ }^{\theta} \mathrm{P}<0.05,{ }^{\theta \theta} \mathrm{P}<0.01$ vs. Coarse particles at Fukuoka at $7.5 \mu \mathrm{g} / \mathrm{mL},{ }^{\#} \mathrm{P}<0.05,{ }^{\# \#} \mathrm{P}<0.01$

501 vs. Coarse particles at Fukuoka at $75 \mu \mathrm{g} / \mathrm{mL} .$.

502

$503 \quad$ Funding sources

504 This work was supported by the Environmental Research and Technology Development Fund 505 (5-1651) of the Ministry of the Environment, Japan, the Matching Planner Program from 506 Japan Science and Technology Agency, JST (MP28116789653), JKA foundation (27-127), 507 Steel Foundation for Environmental Protection Technology, and the Keio Leading-edge 508 Laboratory of Science and Technology (KLL) Specified Research Projects.

510 Acknowledgement: This study was supported by the Environmental Research and 511 Technology Development Fund (5-1651) of the Ministry of the Environment, Japan. The 512 sample collection, preparation, and measurement were performed under the CYCLEX 513 (CYCLone collection of PM2.5 followed by EXposure experiments) project supported by 514 Ministry of the Environment, Japan.

515 We thank Kiyoe Itoi and Yufuko Kobayashi for their technical assistance.

517 Supplementary data: The following are the supplementary data related to this article:

519 Disclosure: The authors declare no competing financial interest.

\section{Reference}


522 Allantaz F, Chaussabel D, Banchereau J, Pascual V. 2007. Microarray-based identification

523 of novel biomarkers in IL-1 mediated disease. Curr Opin Immunol.19, 623-632.

524 Bachert C, van Cauwenberge P, Khaltaev N. 2002. Allergic rhinitis and its impact on asthma.

525 In collaboration with the World Health Organization. Executive summary of the workshop

526 report. 7-10 December 1999, Geneva, Switzerland. Allergy. 57 (9), 841-855.

527 Becker S, Mundandhara S, et al. 2005. Regulation of cytokine production in human alveolar

528 macrophages and airway epithelial cells in response to ambient air pollution particles: further

529 mechanistic studies. Toxicol Appl Pharmacol. 207 (2), 269-275.

530 Brunekreef B, Forsberg B. 2005. Epidemiological evidence of effects of coarse airborne 531 particles on health. Eur Respir J. 26, 309-318.

532 Cachon BF, Firmin S, Verdin A, Ayi-Fanou L, Billet S, Cazier F, et al. 2014.

533 Proinflammatory effects and oxidative stress within human bronchial epithelial cells exposed 534 to atmospheric particulate matter (PM2.5 and PM>2.5) collected from Cotonou, Benin. 535 Environmental Pollution. 185, 340-351.

536 Camatini M, Gualtieri M, et al. 2008. Seasonal and dimensional differences in pro537 inflammatory potency of the atmospheric particulate matter of Milan on lung cell lines. 538 Toxicol Lett. 180S,S97.

539 Carter JD, Ghio AJ, Samet JM, Devlin RB. 1997. Cytokine production by human airway 540 epithelial cells after exposure to an air pollution particle is metal-dependent. Toxicol Appl $541 \quad$ Pharmacol. 146 (2), 180-188.

542 Chao Min Teh, Abdul Rahman Mohamed. 2011. Roles of titanium dioxide and ion-doped 543 titanium dioxide on photocatalytic degradation of organic pollutants (phenolic compounds 
544 and dyes) in aqueous solutions. Journal of Alloys and Compounds. 509 (5), 1648-1660.

545 Chowdhury H Pratiti, Okano H, Honda A, Kudou H, Kitamura G, Ito S, Ueda K, Takano H.

546 2018. Aqueous and organic extract of PM2.5 collected in different seasons and cities of Japan

547 differently affect respiratory and immune systems. Environmental Pollution. 235, 223-234.

548 Dinarello CA. 2005. Blocking IL-1 in systemic inflammation. J Exp Med. 201, 1355-1359.

549 Douwes J, Thorne P, Pearce N, Heederik D. 2003. Bioaerosol health effects and exposure

550 assessment: progress and prospects. Ann Occup Hyg. 47, 187-200.

551 Eun-Jung Park, Jongheop Yi, Kyu-Hyuck Chung, Doug-Young Ryu, Jinhee Choi, Kwangsik

552 Park. 2008. Oxidative stress and apoptosis induced by titanium dioxide nanoparticles in

553 cultured BEAS-2B cells. Toxicol Lett. 180, 222-229.

554 Eun-JungPark, Hero Kim, Younghun Kim, Jongheop Yi, Kyunghee Choi, Kwangsik Park.

555 2010. Inflammatory responses may be induced by a single intratracheal instillation of iron 556 nanoparticles in mice. Toxicology. 275, 65-71.

557 Fuentes-Mattei E, Rivera E, Gioda A, et al. 2010. Use of human bronchial epithelial cells 558 (BEAS-2B) to study immunological markers resulting from exposure to PM2.5 organic 559 extract from Puerto Rico. Toxicol Appl Pharmacol. 243, 381-389.

560 Fukuoka A, Matsushita K, Morikawa T, Takano H, Yoshimoto T. 2015. Disel exhaust 561 particles exacerbate allergic rhinitis in mice by disrupting the nasal epithelial barrier. Clinical 562 \& experimental allergy. 46, 142-152.

563 Gerlofs-Nijland M, Dormans J.A, et al. 2007. Toxicity of coarse and fine particulate matter 564 from sites with contrasting traffic profiles. Inhalation Toxicology. 19, 1055-1069.

565 Grabowsky J, Streibel T, Sklorz M, Chow JD, Watson JG, Mamakos A, Zimmermann R. 
566 2011. Hyphenation of a carbon analyzer to photo-ionization mass spectrometry to unravel 567 the organic composition of particulate matter on a molecular level. Anal Bioanal Chem. 401, 568 3153-3164.

569 Gualtieri M, Ovrevik J, Holme J, et al. 2010. Differnces in cytotoxicity versus pro570 inflammatory potency of different PM fractions in human epithelial lung cells. Toxicology 571 in vitro. 24, 29-39.

572 Heyder J, Gebhart J, Rudolf G, Schiller CF, Stahlhofen W. 1986. Deposition of particles in 573 the human respiratory tract in the size range 0.005-15 $\mu \mathrm{m}$. J Aerosol Sci. 17 (5), 811-825.

574 Hioki T, Kimoto T, Hasegawa S, et al. 2009. Analysis of Long-range Tansported and Air 575 Pollution with Trace Metal Concentration Ratio in Aerosols collected at Matsuyama, Osaka 576 and Tsukuba, Japan. J Jpn Soc Atmos Environ. 44 (2), 91-100.

577 Hiyoshi K, Ichinose T, Sadakane K, Takano H, Nishikawa M, Mori I, Yanagisawa R, 578 Yoshida S, Kumagai Y, Tomura S, Shibamoto T. 2005. Asian sand dust enhances ovalbumin579 induced eosinophil recruitment in the alveoli and airway of mice. Environ Res. 99, 361-368. 580 Honda A, Fukushima W, Oishi M, et al. 2017. Effects of components of PM2.5 collected in 581 Japan on the respiratory and immune systems. International Journal of Toxicology. 36 (2), $582 \quad 153-164$.

583 Honda A, Matsuda Y, Murayama R, et al. 2014. Effects of Asian sand dust particles on the 584 respiratory and immune system. J Appl Toxicol. 3 (3), 250-257

585 Honda A, Tsuji K, Matsuda Y, Hayashi T, Fukushima W, Sawahara T, Kudo H, Murayama 586 R, Takano H. 2015. Effects of air pollution-related heavy metals on the viability and 587 inflammatory responses of human airway epithelial cells. International Journal of Toxicology. 
588

\section{9}

590

591

\section{2}

593

\section{4}

595 596

\section{7}

598

603

606 lines. Toxicol Appl Pharmacol. 229, 146-160.

607 James H, Michelle H, Caitrionna R, Shijuan G, et al. 2011. Autophagy controls IL-1 $\beta$

608 serection by targeting pro-IL-1 $\beta$ for degradation. Journal of Biological Chemistry. 286 (11), 609 9587-9597. 
610 Japan Ministry of the Environment. 2014. https://www.env.go.jp/chemi/report/h24-

611 02/index.html. Updated March 2014.

612 Jiang W, Swiggard WJ, Heufler C, et al. 1995. The receptor DEC205 expressed by dendritic

613 cells and thymic epithelial cells is involved in antigen processing. Nature. 375 (6527), 151-

614155.

615 Kaneyasu N, Yamamoto S, Sato K, Takami A, Hayashi M, Hara K, Kawamoto K, Okuda T,

616 Hatakeyama S. 2014. Impact of long-range transport of aerosols on the PM2.5 composition

617 at a major metropolitan area in the northern Kyushu area of Japan. Atmospheric Environment.

$61897,416-425$.

619 Koh KK, Han SH, Quon MJ. 2005. Inflammatory markers and the metabolic symdrome:

620 insights from therapeutic interventions. J Am College Caardiol. 46, 1978-1985.

621 Koike E, Takano H, Inoue K, Yanagisawa R, Kobayashi T. 2008. Carbon black nanoparticles

622 promote the maturation and function of mouse bone marrow-derived dendritic cells.

623 Chemosphere. 73 (3), 371-376.

624 Kyoung S. Kim, Rajagopal V, Gonsalves C, Johnson C, Vijay K. Kalra. 2006. A Novel Role

625 of Hypoxia-Inducible Factor in Cobalt Chloride- and Hypoxia-Mediated Expression of IL-8

626 Chemokine in Human Endothelial Cells. J Immunol. 177, 7211-7224.

627 Lacasana M, Esplugues A, and Ballester F. 2005. Exposure to ambient air pollution and

628 prenatal and early childhood health effects. Eur. J. Epidemiol. 20 (2), 183-199.

629 Lambrecht BN, Hammad H. The airway epithelium in asthma. Nat. Med. 2012; 18:684-692.

630 Lin C-C, Chen S-J, Huang K-L. et al. 2005. Characteristics of Metals in

631 Nano/Ultrafine/Fine/Coarse Particles Collected Beside a Heavily Trafficked Road. 
632 Environmental science \& technology. 39 (21), 8113-8122.

633 Lindbom J, Mats G, Goran B, Andreas D, et al. 2006. Exposure to wear particles generated 634 from studded tires and pavement induces inflammatory cytokine release from human 635 macrophages. Chem Res Toxicol. 19, 521-530.

636 Lutz MB, Kukutsch N, Ogilvie AL, et al. 1999. An advanced culture method for generating 637 large quantities of highly pure dendritic cells from mouse bone marrow. J Immunol Methods. $638223(1), 77-92$.

639 Marcazzan G, Vaccaro S, Valli G, Vecchi R. 2001. Characterization of PM10 and PM2.5 640 particulate matter in the ambient air of Milan (Italy). Atmospheric Environment. 35 (27), 641 4639-4650.

642 Ming-YieLiu, Wen-ChuanHsieh, Bei-Chang. 2000. In vitro aberrant gene expression as the 643 indicator of lead-induced neurotoxicity in U-373MG cells. Toxicology. 147 (1), 65-71.

644 Miyakawa T, Takegawa T, Kondo Y. 2008. Photochemical evolution of submicron aerosol 645 chemical composition in the Tokyo megacity region in summer. Journal of geophysical 646 research. 113, D14304. Doi:10.1029/2007JD009493.

647 Moncayo-Nieto OL, Wilkinson TS, Brittan M, et al. 2014. Differential response to the 648 bacteria, and TOLLIP expression, in the human respiratory tract. BMJ Open Resp Res. $649 \quad 1: \mathrm{e} 000046$.

650 Monn C, Becker S. 1999. Cytotoxicity and induction of proinflammatory cytokines from 651 human monocytes exposed to fine (PM2.5) and coarse particles (PM10-2.5) in outdoor and 652 indoor air. Toxicol Appl Pharmacol. 155, 245-252

653 Moorhead PS. 1965. Human tumor cell line with a quasi-diploid karyotype (RPMI2650). Exp 
654 Cell Res. 39 (1), 190-196.

655 Mori I, Sun Z, Ukachi M, Nagano K, McLead CW, Cox AG, Nishikawa M. 2008.

656 Development and certification of the new NIES CRM 28: urban aerosols for the 657 determination of multielements. Anal Bioanal Chem. 391, 1997-2003.

658 Ogino K, Nagaoka K, Okuda T. et al. 2017. PM2.5 - induced airway inflammation and 659 hyperresponsiveness in NC/Nga mice. Environ Toxicol. 32 (3), 1047-1054.

660 Okamoto K. 1987. A new certified reference material, vehicle exhaust particulates. 661 Analytical sciences. 3, 191-192.

662 Okuda T, Isobe R. 2017. Improvement of a High-volume Aerosol Particle Sampler for 663 Collecting Submicron Particles through the Combined Use of a Cyclone with a Smoothened 664 Inner Wall and a Circular Cone Attachment. Asian Journal of Atmospheric Environment. 11 665 (2), 131-137.

666 Okuda T, Isobe R, Nagai Y, Okahisa S, Funato K, Inoue K. 2015. Development of a high667 Volume PM2.5 Particle Sampler Using Impactor and Cyclone Techniques. Aerosol and Air 668 Quality Research. 15, 759-767.

669 Okuda T, Schauer J, Shafer M. 2014. Improved methods for elemental analysis of 670 atmospheric aerosols for evaluating human health impacts of aerosols in East Asia. 671 Atmospheric Environment. 97, 552-555

672 Okuda T, Shishido D, Terui Y, Fujioka K, Isobe R, Iwaki Y, Funato K, Inoue K. 2018. 673 Development of a high-volume simultaneous sampler for fine and coarse particles using 674 virtual impactor and cyclone techniques. Asian Journal of Atmospheric Environment. 12 (1), $675 \quad 78-86$. 
676 Okuda T, Takada H, Kumata H, Nakajima F, et al. 2013. Inorganic Chemical Characterization 677 of Aerosols in Four Asian Mega-Cities. Aerosol and Air Quality Research. 13 (2), 436-449.

678 Okuda T. 2013. Measurement of the specific surface area and particle size distribution of 679 atmospheric aerosol reference materials. Atmospheric Environment. 75, 1-5.

680 Park EJ, Park K. 2009. Induction of pro-inflammatory signals by 1-nitropyrene in cultured 681 BEAS-2B cells. Toxicol Lett. 184, 126-133.

682 Pascal LE, Tessier DM. 2004. Cytotoxicity of chromium and manganese to lung epithelial 683 cells in vitro. Toxicol Lett. 147 (2), 143-151.

684 Perez IR, Serrano J, Alfaro-Moreno E, Baumgardner D, Garcia-Cuellar C, Martin del Campo 685 JM, Raga GB, Castillejos M, Colin RD, Osornio-Vargas AR. 2007. Relations between PM10 686 composition and cell toxicity: a multivariate and graphical approach. Chemosphere. 67, $687 \quad 1218-1228$.

688 Querol X, Zhuang X, Alastuey A, Viana M, Lv W, Wang Y, Lopez A, Zhu Z, Wei H, Xu S. 689 2006. Speciation and sources of atmospheric aerosols in a highly industrialised emerging 690 mega-city in Central China. J Environ Monit. 8, 1049-1059.

691 Riley MR, Boesewetter DE, Kim AM, Sirvent FP. 2003. Effects of metals Cu, Fe, Ni, V, and 692 Zn on rat lung epithelial cells. Toxicology. 190 (3), 171-184.

693 Samoli E, Peng R, Ramsay T, Pipikou M, Touloumi G, Dominici F, Burnett R, Cohen A, 694 Krewski D, Samet J, Katsouyanni K. 2008. Acute effects of ambient particulate matter on 695 mortality in Europe and North America: results from the APHENA study. Environmental 696 Health Perspective. 116 (11), 1480-1486.

697 Schins RPF, Lightbody JH, Borm PJA, Shi T, Donaldson K, Stone V. 2004. Inflammatory 
698 effects of coarse and fine particulate matter in relation to chemical and biological constituents. 699 Toxicology and Applied Pharmacology. 195, 1-11.

700 Schmalz G, Schuster U, Schweikl H. 1998. Influence of metals on IL-6 release in vitro. 701 Biomaterials. 19, 1689-1694.

702 Schwartz J, Lucas M. 2000. Fine particles are more strongly associated than coarse particles 703 with acute respiratory health effects in schoolchildren. Epidemiology. 11 (1), 6-10.

704 Sevastyanova O, Novakova Z, Hanzalova K, Binkova B, Sram R, Topinka J. 2008. Temporal 705 variation in the genotoxic potential of urban air particulate matter. Mutation Research. 649, $706 \quad 179-186$.

707 Sharma H, Jain VK, Khan ZH. 2007. Characterization and source identification of polycyclic 708 aromatic hydrocarbons (PAHs) in the urban environment of Delhi. Chemosphere. 66, 302709310.

710 Takegawa N, Miyakawa T, Kondo Y, Blame DR, Kanaya Y, Koike M, Fukuda M, Komazaki

711 Y, Miyazaki Y, Shimono A, Takeuchi T. 2006. Evolution of submicron organic aerosol in 712 polluted air exported from Tokyo. Geophysical research letters. 33. L15814. 713 Doi:10.1029/2006GL025815.

714 Takami A, Miyoshi T, Irei S, Yoshino A, Sato K, Shimizu A, Hayashi M, Hara K, Kaneyasu 715 N, Hatakeyama S. 2016. Analysis of Organic Aerosol in Fukuoka, Japan Using a PMF 716 Method. Aerosol and Air Quality Research. 16, 314-322.

717 Taniguchi Y, Shimada K, Takami A, Lin NH, Chan CK, Kim YP, Hatakeyama S. 2016. 718 Transboundary and Local Air Pollutants in Western Japan Distinguished on the Basis of 719 Ratios of Metallic Elements in Size-Segregated Aerosols. Aerosol and Air Quality Research. 
17 (12), 3141-3150.

721 Tecer LK, Alagha O, Karaca F, Tuncel G, Eldes N. 2008. Particulate Matter (PM $2.5, \mathrm{PM}_{10-2.5}$, 722 and $\mathrm{PM}_{10}$ ) and Children's Hospital Admissions for Asthma and Respiratory Diseases. J 723 Toxicol and Env Health. 71 (8), 512-520

724 Thacker EL. 2006. Lung inflammatory responses. Vet Res. 37 (3), 469-486.

725 Totlandsdal AI, Herseth JI, Bølling AK, Kubátová A, Braun A, Cochran RE, Refsnes M, 726 Ovrevik J, Låg M. 2012. Differential effects of the particle core and organic extract of diesel 727 exhaust particles. Toxicol Lett. 208, 262-268.

728 U.S. Environmental Protection Agency. 1995. Air Quality Criteria for Particulate Matter. 729 EPA/600/AP-95/001b. Research Triangle Park, NC: U.S. Environmental Protection Agency. 730 Vecchi R, Marcazzan G, Ceriani M, Antoniazzi C. 2004. The role of atmospheric dispersion 731 in the seasonal variation of PM1 and PM2.5 concentration and composition in the urban area 732 of Milan (Italy). Atomospheric Environment. 38 (27), 4437-4446.

733 Yamada P, Hatta T, Du M, Wakimizu K, Han J, Maki T, Isoda H. 2012. Inflammatory and 734 degranulation effect of yellow sand on RBL-2H3 cells in relation to chemical and biological 735 constituents. Ecotoxicol Environ Saf. 84, 9-17.

736 Zerbi G, Ferruggiari A, Fustella G, Tommasini M, Mantecca P, Gualtieri M, Cetta F, 737 Camatini M. 2008. Preliminary observation on the interactions between fine atmospheric 738 particulate matter (PM2.5) and human alveolar epithelial cells (A549). Chemical Engineering 739 Transaction. 16, 387-394. 